\title{
Article
}

\section{Assemblage Theory and the Capacity to Value: An Archaeological Approach from Cache Cave, California, USA}

Robinson, David Wayne

Available at http://clok.uclan.ac.uk/17248/

Robinson, David Wayne ORCID: 0000-0002-0729-5011 (2017) Assemblage Theory and the Capacity to Value: An Archaeological Approach from Cache Cave, California, USA. Cambridge Archaeological Journal, 27 (1). pp. 155-168. ISSN 0959-7743

It is advisable to refer to the publisher's version if you intend to cite from the work. http://dx.doi.org/10.1017/S0959774316000639

For more information about UCLan's research in this area go to http://www.uclan.ac.uk/researchgroups/ and search for <name of research Group>.

For information about Research generally at UCLan please go to http://www.uclan.ac.uk/research/

All outputs in CLoK are protected by Intellectual Property Rights law, including Copyright law. Copyright, IPR and Moral Rights for the works on this site are retained by the individual authors and/or other copyright owners. Terms and conditions for use of this material are defined in the policies page.

\section{CLoK}

Central Lancashire online Knowledge www.clok.uclan.ac.uk

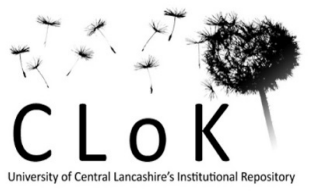


Assemblage Theory and the Capacity to Value: An Archaeological Approach from Cache Cave, California, USA

\section{David Robinson}

Received 12 Feb 2016; Accepted 20 Oct 2016

New discoveries from a Californian cave have found a remarkable assemblage of cached perishable and other artefacts. Comprised of baskets, cordage, bone, antler, leather, food residues and other materials, the assemblages are dispersed through four caves in the largest ever cache discovered in the borderland region attributable to the native Californian linguistic group known as the Chumash. This paper develops a methodology based upon DeLanda's philosophy of assemblages and Graeber's anthropological theory of value. Importantly, following Normark, it is argued that assemblage theory needs to be operationalized into a methodological approach in order to apply it archaeologically. This methodology illustrate how a capacity analysis of the Cache Cave assemblage relates to values within the society which cached it by revealing the relational capacities within assemblages and relative capacities between them. Importantly, as a scalable approach, capacity analysis allows the investigation of the heterogeneous dynamics within complex societies.

When winnowing chia, Fernando was told that this world is merely a great flat winnowing tray. Some men move up and some down. And there is much chaff mixed through it all. (Blackburn 1975, 97)

This quote from the Chumash of south-central California illustrates the polysemous values that basketry obtains within indigenous south-central Californian society (Fig. 1). The winnowing basket acts to winnow, or separate non-edible husk and bits of shell in seed-foods such as the tiny chia seed from the edible meat of the seed itself. To do this requires certain properties such as a relatively flat tray, ideally with a flared rim small enough to manoeuvre with two hands but large enough for a reasonable amount of meal: the tossing of the chia seeds into the air allows the wind to blow away the chaff. The properties of the basket and how it is employed come together to provide metaphorical value to discuss the movement of people within society. This is one way that the basket's capacity acts in an agentive or affective manner within the Chumash world. Equally, this very brief oral account gives an evocative glimpse into indigenous values of social status and movement. And, if we see the winnowing tray, the chaff, the storyteller, the audience and the society as parts of an assemblage, then such assemblages have political dimensions.

One of the strengths of assemblage theory is that it is tacitly concerned with the political. From Deleuze and Guatarri (1987) to DeLanda (2006; 2016) and Bennett (2010), these authors have promoted assemblage theory as a means to address modernity critically and offer a kind of manifesto to effect change in contemporary 
society. This dimension of assemblage theory has gained purchase across disciplines. From the standpoint of geography, Anderson et al. state (2012, 214): 'assemblage moves between its appearance as a concept and something that directs inquiry and can be invoked in acts of political struggle and intervention'. Biehl and Locke (2010) employ a Deleuzian approach to unpacking the biopolitics of the poor and institutional psychiatry in the anthropology of becoming by speaking of such an approach as having the 'potential to become a mobilizing force in this world' (2010, 337). The widening application of assemblage theory in disciplines such as geography and anthropology clearly demonstrate its attractiveness for work explicitly concerned with the modern and contemporary world (see Harrison 2011). This strength, of course, calls into question how applicable it may be to the study of other forms of society which are often the focus of archaeologists, but its attractiveness for our discipline in part is derived from its explicit 'realist' ontology recognizing the affective quality of the material dimension. As part of the wider 'ontological turn' in the academy (Escobar 2007; Escobar \& Osterweil 2010, 189-94), assemblage theory clearly resonates with recent archaeological trends concerned with affect, agency and affordance, particularly within the material dimension. Also, influenced from various quarters including Actor Network Theory (e.g. Latour 2005), ethnographically derived ideas from New Animism (e.g. Bird-David 1999), and the symmetrical archaeology 'movement' (Shanks 2007: Witmore 2007), recent work has shifted focus to non-human actants, effectively decentring the human as the prime focus of inquiry (see Dowson 2007; 2009). Just as Bennett's (2010) vital materialism challenges the human hubris of an anthropocentric claim of privilege over the material, Normark's (2009; 2010) work with Mayan households and causeways decentres the human by moving towards what he terms an 'anorganic' perspective, with archaeological assemblages seen as a process of 'becomingmateriality' rather than follow normative archaeological narratives. While this line of ontological decentring is promising, with a trajectory yet to be fully worked though (see Fowler 2013 for arguably the most developed realist approach), in this paper I develop a methodological approach in order to understand the value of those assemblages in past human communities. In this case, I focus intently on the concept of capacity, a fundamental principle for DeLanda (2006) in the actualization of an assemblage.

For DeLanda (2006), the value of assemblage theory is that it allows for a multiscalar explanation for societal complexities, while avoiding the pitfall of reifying our categorical notions of society as actualized totalities. It is because of this scalability that assemblage can look at the person, an organization, cities, or states, but also is particularly attractive to archaeologists because of the explicit recognition of the importance of materiality and its various capacities as an active force in human history. However, adopting assemblage theory as a straightforward model within which to 'plug' archaeological data runs the risk of simply reifying the theory as a metanarrative (which is exactly what assemblage theorists decry). Ingold $(2014,235)$, in a recent critique of New Materialism and Symmetrical archaeology, warns that 
such approaches risk reducing the human/material to a new kind of tautology where the archaeological records is reduced to endless connections and effects with 'no production-no work, no labour, no growth'. In the context of this special issue, I will argue how Ingold's critique really misses the point of neo-materialist approaches, of which assemblage theory certainly articulates with, by showing that work and labour are indeed critical aspects of assemblage theory. However, human creativity and technological design are equally important within these theories. I argue here that it is an object's capacity in relation to its wider assemblage which ultimately allows us understanding of the value of material culture within human society, in this case study of the Chumash and Cache Cave. Importantly, in the context of this special issue, the results of this analysis highlight the value of assemblage theory as a methodological means to interpret the human past.

Typically couched within processual notions of complexity, archaeologists studying the Chumash focus on social hierarchy based upon the control of craft production of beads, the construction and control of canoes, and extended networks of exchange and power (Arnold 2001; Gamble 2008). Very little attention has been given to the role of basketry and other perishables, even though we know from ethnographic accounts that these likely accounted for over 65 per cent of the entire material repertoire of the Chumash (Gamble 2008). Indeed, for the Chumash and other indigenous Californians, basketry sat at the core of economic, household and other practices. As Ralph Shanks $(2010,1)$ states, 'Californian Indian basketry is the most diverse, complex and magnificent basketry in the world'. The rich, diverse, biotic flora of California provided an astonishing variety of material from which to make these perishable objects. Importantly, the making of baskets is almost universally attributed to women (Shanks 2010). Because of this, I argue that the wealth of households was very much linked to women's notions of craftsmanship and skill in the making of both individual objects and the variety of objects that were valued within wider indigenous Californian society. Ethnographic photographs (Fig. 2) often illustrate how families liked to show off the baskets of a particular household and the ethnographic record is replete with accounts of esteemed women basket makers. Baskets were used for every aspect of domestic life: to collect, to transport, to process, to cook, to store, to gamble, to wear and to use in ceremonies. The issue for archaeologists, however, is the fact that basketry is rarely discovered in quantity, in good condition, or in documented contexts; this limits our ability to analyse this critical facet of hunter-gatherer material culture.

The recent work we have been doing at the remarkable site of Cache Cave offers the chance to redress this imbalanced perspective. Located within the interior Emigdiano Chumash borderlands (Fig. 3), our recent fieldwork there has uncovered the largest perishable assemblage so far discovered in south-central California. The term 'cache cave' is a colloquial term for caves or rock-shelters that were utilized for the placement of material culture, especially perishable items such as baskets. Because of a long tradition of looting and collecting, very few cache sites remain extant. Based upon museum collections and information largely retrieved from 
collectors, recent research has identified over 80 such known sites, with a total of 845 finds (Whitby 2012; see also Robinson et al. 2012). This paper focuses on the assemblage from excavations in 2012. Work within four different caves produced over 1100 finds, as well as large quantities of raw materials, eclipsing the total from all previously known cache cave sites combined (Figure 4). This includes 189 basketry pieces; 223 pieces of cordage; hundreds of pieces of bone, asphaltum, reeds, cane, or bark; two self-pointed arrows and a decorated arrow shaft; hundreds of pieces of wood, charcoal, and seeds, plus marine and lacustrine shell; pieces of feathers or quills; six pieces of leathery objects; antler objects; bone tools, and shell beads.

While no such cache complex has been documented before in the greater south-central Californian region, there has been a long-standing if very sporadic attention given to Chumash cache caves in particular. Mohr and Sample (1967) discussed objects from other cache caves within the larger concept of 'sacred bundles' ethnographically evident in other southern Californian native groups. While Whitby's (2012) research on cache caves looked at them in part from the idea of wrapping, this idea of bundling has gained purchase in other research across the continent. Indeed, Pauketat's (2013) work has taken bundling as a means to understanding Big History via multi-scalar and multidimensional interconnectivities that describes what we may more generically call 'society' or 'culture'. This metanarrative view is intriguing, but too broad and encompassing to usefully understand the particularities of archaeological assemblages such as found at Cache Cave. Zedeño's (2008) recent rethinking of Plains Indian bundles is far more relevant. Zedeño $(2008,362)$ states that Plains Indian 'Bundles, like persons, are subject to hierarchical and heterarchical power relations that parallel societal relations within tribal groups'. However, there are fundamental differences in what Zedeño discusses (i.e. the specific phenomena of Plains Indian bundles, which were a category of conjoined object assemblages that were carried or distributed hand-tohand) against the wide range of materials cached in a variety of contexts within the confines of this Californian cave system. If we take Zedeño's fundamental proposition, that bundles are a kind of non-human person in relation to the human possessor in care of that bundle, then we are dealing with a relationship where the bundle is a simulacrum of the human possessor. This is important because, from an analytical point of view, it implies that by looking at the bundle, the persona of the human who 'owns' that object-bundle may be revealed. DeLanda (2006) argues that assemblages are composed of 'entities', or more simply 'components', that come together to give an identity to that assemblage. Importantly, DeLanda (2006) states that an assemblage's identity is recognizable through the expression of the components capacities (rather than properties: see discussion below) which result through the interaction with other components within the assemblage. In archaeological terms, it follows that the study of assemblages attuned to the capacities of constituent components can help to deduce not only the assemblage itself, but the human identity or persona enacted in the relationship as evidenced by 
character of the overall assemblage. As will be illustrated, such an analysis is ideal for the assemblages discovered at Cache Cave.

In order to investigate this, we need to unpack DeLanda's $(2006 ; 2012)$ concept of capacity, an idea that is fundamental for understanding object agency and the formation of assemblages. DeLanda acknowledges (2002) using the concept of capacity to explain the Deleuzian term 'affect', which itself is closely related to Gibson's (1979) notion of 'affordance.' Gibson's idea of affordance, being first and foremost concerned with shape and form, is more commonly allied to visual perception and less commonly to the wider palette of dimensions that can be considered as affectual. This explains how affordance is usefully used in GIS studies of viewsheds (Gillings 2012), but rarely used in least cost path analyses (except for instance, Lock et al. 2012). In turning to the concept of capacity, DeLanda describes a relational process that can equally accommodate movement as much as visual perception, as well as innumerable other potential affects that constitute assemblages human, animal, or otherwise. According to DeLanda (2012), material entities have both properties and possible capacities. A capacity is latent, or virtual as he puts it, in the sense that its properties have the possibility to act in an affective manner, but the capacity may or may not be exercised. In order for a capacity to become exercised, it does so via some kind of catalyst. Usefully, DeLanda $(2012,13)$ differentiates between properties, virtual capacities and exercised capacities with an example of a manufactured knife with its sharp blade and an obsidian rock with a naturally sharp edge:

... a knife has the actual property of being sharp and the virtual capacity to cut. If we imagined instead of a manufactured object a sharp obsidian stone existing before life, we could ascribe to it that same capacity to cut, a capacity it occasionally exercised on softer rocks that fell on it. But when living creature large enough to be pierced by the stone appeared on this planet the stone suddenly acquired the capacity to kill. This implies that without changing any of its properties the possibility space associated with the capacities of stone become larger.

So, to reiterate, a manufactured knife or an obsidian edge each have the property of being sharp, but each also has the virtual capacity to cut. It is only by being enacted by a catalyst (i.e. either by human hands or rock fall) that the capacity becomes expressed or exercised. If circumstances around an entity change, its relations to other entities may therefore change; then its capacity can likewise change, in this case enlarged to the capacity to kill. The key point here is that component elements must have expressive capacities in order for them to express an identity as an assemblage. This means that we should be looking, not simply to detail the properties of archaeological material, but to analyse the specific capacities of the components of our archaeological assemblages and attempt to understand which capacities were in fact exercised in the past, if we wish to understand the character of 
that assemblage as it relates to the human. However, a caveat is warranted here: DeLanda $(2012,13)$ points out that 'capacities are potentially infinite in number because they depend not only on the power of an entity to affect but also on that of innumerable other entities to be affected by it'. The difficulty then lies in adjudicating which capacities to focus on. In other words, if capacities are infinite, we have to make decisions as to which ones are most relevant, which requires making value judgements. Fortunately, we are able to home in on certain capacities because of our specific interest in the human engagement within the assemblage, and have the specific archaeological and anthropological traditions of research from which we can attune that capacity analysis.

It is pertinent, then, to discuss the notion of value. Here, I draw upon Graeber's $(2001,254)$ anthropological theory which defines value as the 'way actions become meaningful to the actors by being placed in some larger social whole, real or imaginary'. By 'actions', Graeber is clear that he means the capacities that become actualized between objects and people. Graeber $(2001,260)$ puts forward that objects are ascribed value through their 'potentials' and 'capacities' in coordination with others, foreshadowing some of DeLanda's concepts. For instance, he uses an example of a Maori garment:

A lord's cloak, or in fact any garment, was part of that lord and often seemed to represent that very capacity for encompassment: to throw one's garment over a prisoner meant that person was spared from death; an important unmarried women who threw her cloak over a man thereby married him. (Graeber 2001, 173)

This example shows how what typically would be considered the polysemous value of the cloak as an object was in fact due to its capacity to encompass, actualized through the catalyst of different Maori actions. Value in terms of material culture is the result of human action in the creative process of making and in the material capacities enacted within the community as experienced by the community. For the Maori, a certain invisible 'vital essence' (called hau or mauri) is the emanation behind any material form and its potential for actions (Graeber 2001, 177). While not exactly equivalent, this is close to Bennett's (2010) vital materialism concept whereby materiality is ascribed its own agency and DeLanda's view $(2011,15)$ that matter is actively 'endowed with its own tendencies and capacities ... animated from within by immanent powers of being and becoming'. As already mentioned, such happenings in the material world go on without human attention or even evaluations of those material emanations. This is why the symmetrical archaeology or neo-materialism agenda has legitimacy, because agency is not the transcendent monopoly of our species alone. But, from the human perspective, those capacities of materiality do become important through the inter-personal process of valuation. As Graeber $(2001,70)$ puts it, value is contrastive and can only become realized in a public context. Value is, in human practice, not symmetrical, but asymmetrical. This 
asymmetry can emerge via the relations between different objects and the relative properties between similar objects.

So, rather than ascribe an a priori essential value to an object or an assemblage, we must look instead at the relative and relational capacities objects manifest in order to approach value within a specific historical context. Relational value is constructed within the assemblage itself through the interplay of the components which ultimately forms the persona or identity of that assemblage. Different assemblages, therefore, may have categorically different capacities which are valued in ontologically different manners and so are not comparable in any straightforward fashion in terms of the value between one another. On the other hand, relative value is comparative when analysing similar capacities across assemblages; this allows for comparing the value across assemblages rather than simply within an assemblage. From an analytical perspective, relational value is primarily qualitative, while relative value is primarily quantitative. What is important is that the objects of concern in Cache Cave are those made and used by people, so that they are imbricated within the human creative process, which in Graeber's terms constitutes the process of creating value. Value is therefore very much a part of human assemblages and can be approached through a capacity analysis.

\section{Capacity analyses and relational value}

To illustrate how a capacity analysis may lead to understanding assemblages in terms of their relational value, we look at the makeup of the assemblages found within the Cache Cave complex by first examining Cave 3. Upon discovery, objects were seen strewn across this small cave within a discrete $2 \times 3 \mathrm{~m}$ floor space (Fig. 5 ). The assemblage includes antler and elk bone scapula saws with leather grips or sheaths, antler wedges, a single lithic drill, cordage, plus a wide array of basketry including two large storage baskets, a near-complete water bottle and several trays or lids, including a highly decorated parching tray. Analysis of the smaller fragments indicates that up to six water bottles and eight parching trays were present. Some of the trays include a heavy residue meal-like substance, likely chia, buckeye, or acorn. The capacity that these objects embody is revealing.

The bone tool saws and chert drill have capacities for working soft or semisoft raw materials such as leather or wood. The scapula saws are particular good for cutting stemmed vegetal matter such as bunch grasses, reeds, and canes. Tall, robust native Californian grasses were the most important material used in making baskets, while reeds and canes were used for a range of perishable items (Shanks 2010; Timbrook 2007). The semi-bowl-like design of the trays allows for the continuous rolling of hot rocks to cook meal, or to parch seeds. Importantly, the shape of these trays, wide mouthed, somewhat shallow, and with flared sides, enables a clear view of the material in the basket and the continual movement of a relatively shallow meal. This capacity lends itself to other food-processing tasks, including some forms 
of winnowing, sifting and leaching, so that basket 'trays' are known to have been used in more than one practice.

The property of water bottles, twined and then coated with asphaltum to make them watertight, obviously had the capacity for the transport and storage of water away from water sources. This enables not only simple storage for drinking purposes, but more importantly facilitates cooking to take place (in combination with other vessels), as water was crucial to cooking a variety of foods. The storage baskets, with their wide and deep forms, had the capacity to store large quantities of foods, or even items of material culture. They could be used as stationary objects, or, modified with a carrying strap, be used in the field in the gathering process.

In total, it is clear from the assemblage that a full range of capacities associated with engaging with perishable material culture can be seen in Cave 3. First, objects were used in the acquisition, making and maintenance of possibly wood and leather, but certainly basketry material. Primary capacities include the storage, processing and cooking of seed foods needed to facilitate those practices. Analysis of the assemblage shows that these are not pristine objects, but have evidence of extensive use, wear, repair and some repurposing demonstrating that all of these capacities had been actualized rather than remaining virtual. The interrelation of these capacities, then, shows an identity of the overall assemblage. Relations of capacities within the Cave 3 assemblage show a strong identity oriented to preparing material for the making of basketry, the gathering and transport of those materials and food-stuff, plus clear evidence for cooking and potentially eating or sharing of foods. The assemblage indicates a capacity greater than just an individual, but equally not likely to serve a whole community. Instead, it seems to match well the scale of a household.

If we next look at the assemblage of Cave 1, there is a reiteration of similar capacities; up to nine parching trays, and fragments indicating multiple water bottles are suggested by the total basketry assemblage, indicating cooking and storage. Scapula saws and an exquisite chert knife have likewise been recovered, showing similar capacities of harvesting/cutting, transport, cooking and storage. Just as with Cave 1, the assemblage appears larger than that of an individual, likely representing a scale consistent to a household cache.

Cave 2 indicates different capacities within its assemblage. With no bone tools whatsoever, it has evidence of only one water bottle and one parching tray. It is instead characterised by a high quantity and proportion of cordage, including significant pieces of netting, as well as a modest assemblage of small flakes. The capacity represented here is something different: rather than cooking and storage, we have material culture based upon catching or ensnaring, as in traps, netting or fishing lines. The flake assemblage has the capacity for cutting, flailing, or quite likely scraping, all capacities needed to transform fibres from raw plant material into string and then in turn to make cordage. Thus, the capacities reflected in Cave 2 are oriented to different material engagements, still one highly focused on plant material, but for net and cordage making, for ensnaring, trapping or fishing. Rather 
than a household cache, this appears to represent some in situ working of cordage and caching of netting by a small group of individuals dedicated to similar tasks.

There are other relational capacities within the assemblage, and indeed context is quite important. Crevice 1, located in Cave 1, was hidden from ready view under a large rock overhang and obscured by dry-stone walling. Within this context, a patch of unique objects was cached at the midpoint of this walling (Fig. 6). This included a coyote femur tube, a modified mammal rib and a bald eagle skull and beak pendant. The capacity of these objects implies bodily adornment: both the tube and the eagle beak can be worn as components of a necklace, while the mammal rib (too large to be an awl) could have been worn as a hair pin. However, it is clear from ethnographic accounts that there may be quite different capacities to these objects than those in the aforementioned assemblages. The coyote femur tube could be used as a healing sucking tube, while the eagle beak pendant is likely to have been an atiswin, a personal power object which held relational links to notions of animal agency and the affective abilities of eagles (Robinson 2004; 2013a,b). Coyotes were often equated with 'doctoring' while eagles were the personification of chiefly power within Chumash and neighbouring groups. Deer likewise were imbricated within complex notions of affect: one Chumash ethnographic account details how a bundle consisting of a tobacco concoction, seeds and shell was opened at a Deer Urine spring in order to induce rain; another ceremony, including a dancer with deer antlers and deer tibia whistle accompaniments, equated the 'spirit of the world' with that of the 'ear of a deer' (Hudson et al. 1977, 45-6, 65). So even the bones of a prey animal may say much more than simply that the animal was hunted for food or that bones have only functional aspects. I have argued (Robinson 2013a) that parts of animals were combined to enact transmorphic processes which were imbricated within Chumash ontological notions of power. Within indigenous terms, the objects in Crevice 1 may do more than simply symbolize the power of animals; they potentially retain a virtual capacity that the animals (or animal component parts) themselves held. These may have been amplified or altered in the alchemical polyvalent combination with other pieces of the assemblage (Robinson 2013c). The wearing of these objects by their human owner thus assembles various capacities in multi-complex relational manners that at once broadcasts the potential capacity that person may wield with that assemblage, while at the same time creating the character and status of the person wearing them.

\section{Capacity analysis and relative value}

Another way to envision the capacity within assemblages is by considering the making of, rather than the use of, the objects. In this sense, the capacity can be seen in the 'raw' materials themselves, in the plants, how they grow, their structural and chemical properties and how they react and thus express capacity in the process of being transformed into a basket, in addition to the tools used to help that process and, of course, the hands of the maker herself. The making of basketry is a skill, and 
requires a process that elides human/plant entanglements (van der Veen 2014). The capacity of bunch grass and other material lends itself to the possibility of differential choice in terms of vessel density, but the making of basketry requires conscious decisions of time investment in gathering, curating and making. So one consideration is the way twining, coiling and stitching take time. As mentioned at the start, California basketry is considered by many to be amongst the finest ever made on the planet. There are reasons for this: the sheer variety of forms and plant materials used is one reason-decoration is another. However, most impressive is the 'tightness' of construction. This requires time, and it is clear that time investment into the making of material culture was one reason for ascribing value. For instance, beads that required the most amount of time to make were the most valued within wider Native Californian economies and operated as a form of currency. Coiling density, as a property, has a virtual capacity in terms of cooling processes related to fluid retention and heat absorption/distribution. But equally tightness of coil gives a vessel the capacity to signal status within the community. It can clearly codify the creative capacities of the maker herself, which is part of the process of creating and elevating the identity of a basketmaker. So comparing the density of coiling and stitching is one way that value can be considered in a relative way between assemblages, rather than simply within them.

While work needs to be completed on the entire assemblage with its myriad small fragments, a preliminary density analysis of the more intact vessels from all the caves was undertaken. As seen in Figures 7 and 8, Caves 3 and 4 have the highest coiling density and stitches per centimetre within their assemblages. Decoration can also be seen as a property than can in turn express a capacity within social settings. The only decorated basketry pieces so far discovered are two that come from Cave 3 (Figure 9), with one piece from Crevice 1 in Cave 1. In Cave 4, a decorated broken pole was located in association with the one highly coiled/stitched tray found there. From these data, some relative values can be proposed. It appears that a different, arguably greater, value can be attributed to the overall basketry assemblage in Cave 3 (and possibly Cave 4). Simply put, these are the places where the most decorated baskets which also requiring the most time and skill to make were cached. The assemblage in Cave 3, while being similar to that in terms of its internal relational capacity as that of Cave 1, is different in its overall capacity to signify a higher degree of craftsmanship.

This brings us to an as yet unmentioned major aspect of each assemblage in terms of capacity: that of the cave system itself. First, the cave system has the capacity to provide an environment for the preservation of perishables in protection from the elements. It is clear that this capacity was consciously recognized by the people who used it to cache in that very little in the way of lithic artefacts is cached; no ground stone has been discovered, and very little debitage and few projectiles. The vast majority of all the material culture is precisely the type of perishable material that does not typically survived in open-air locations. Going along with this, the caves have what might be termed a negative capacity in terms of habitation: 
with the exception of some space in Cave 2, there is a lack of good room. Comprised of a mudflow breccia, this cave system is composed of a jagged boulder-defined rock-shelter system with myriad crawlspaces, crevices, connecting alcove areas and micro-shelters. Even while providing relief from the Californian heat, the shelters are thus small, cramped and uncomfortable.

Lighting is also highly variable, with shafts of light illuminating portions of Cave 1, ambient light illuminating Cave 2, but quite dark spaces found in crevices, Cave 3 and the interior of Cave 4. Finally, there are different capacities in terms of access and movement: for DeLanda (2011), the concept of 'gradients' is central to propositions concerning the emergence of assemblages (see also Robinson \& Wienhold 2016). DeLanda $(2011,9)$ states that 'gradients can serve to generate the moving parts of a larger whole', thus DeLanda conceptualizes gradients as facilitating energy transfers which occurs due to differences in domains as diverse as thermal dynamics to status differentiation in human society. The gradient within the cave system, as well as outside within the steep canyon, provides a virtual capacity enabling/hindering access to the different caves. Caves 1 and 2 are relatively easy to enter: Cave 3 requires climbing up and into the dark recesses of Cave 1, then dropping down into the chamber-like Cave 3 from above. Cave 4 is separated from Caves 1 to 3 and requires a difficult climb up a rather precipitous rock-face and then along a long narrow crack till the caching point is reached. The capacity of the cave system therefore lends itself to different values in terms of access: it is noticeable that the potentially greater valued objects are in dark areas (such as in Crevice 1 in Cave 1) and in more difficult to reach places, such as Caves 3 and 4 . The capacity of effort that the assemblages in these caves give evidence to in terms of their coiling and stitching is, in other words, reflected by the higher effort required simply to reach, deposit or recover them.

\section{Conclusion}

Of what value is assemblage theory to archaeologists? While neo-materialist approaches are right in highlighting material agency, assemblage theory does not postulate an equivalency within components of assemblages. Instead, components are seen as heterogeneous, and therefore have potential differential influences within assemblages. This means that a capacity analysis can potentially distinguish the working of many different kinds of values within any cohesive human community, rather than focusing strictly upon models of top-down hierarchies. As I mentioned in the beginning, archaeologists looking at Chumash complexity have mostly been interested in inequalities of power relationships primarily enacted through the control of specialized craft production, such as canoe and bead making. Less attention has been given to the dynamic range and subtleties of identity within more heterarchical contexts in the Chumash world, such as at the level of household craft production of basketry and other textile practices (see Robinson 2007). In DeLanda's most recent publication on assemblage theory, he makes the point in considering 
technology and human labour that 'design, both functional and aesthetics, also produces value, as does the organisation of production' (Delanda 2016, 45). The case study presented here, looking at the technical design of basketry and other capacities of the assemblages at Cache Cave, illustrates how assemblage theory enables teasing out heterarchical dynamics of Chumash material practice which works alongside more conventional notions of complexity. Delanda's (2006) philosophy of social complexity has within it a scalable capacity which can be operationalized to explore those dynamics especially in the case where such excellent preservation is present such as at Cache Cave. Because DeLanda's (2006) social philosophy focuses on multiple scales, from persons and networks to organizations and governments, on to cities and nations, it is well positioned to engage with long-standing anthropological and archaeological approaches to social complexity.

At Cache Cave, the evidence from the capacity analysis presented above indicates that the assemblages there represent household and individual caches, rather than a corporate controlled storage. It thus illuminates aspect of interpersonal relationships more akin to the person and network scale rather than an institutional scale within DeLanda's (2006) paradigm. To reiterate, this is important because it allows a detailed analytical appreciation within heterarchical dynamics, rather than that of the elite control typical of Chumash complexity studies. DeMarrais' (2013) recent study of pottery in pre-Hispanic Argentina show the utility of exploring heterarchical craft production. She argues that craft production could be produced for circulation in the building of interpersonal networks, as well as for potential use in ritual (DeMarrais 2013, 358). This point is well taken; however, the assemblages from Cache Cave point out that objects do not have equivalent capacities, either in a qualitative or a quantitative sense. Additionally, the deposition within the cave system shows a differential use of space. These relative differences illustrate that objects, spaces and their capacities obtained a variety of values and reflected a range of human personae who ultimately engaged in caching. Just as a highly skilled basketmaker gained status in her community because of the quality of objects fashioned, there are many micro-hierarchical relationships within heterarchies that a capacity analysis can potentially reveal. We can, with a careful eye to capacity in its various outpourings, consider the shifting capacities within assemblages and see value itself as a desirable capacity that is emergent from knowledgeable, skilled, human creative practices. Further, by asking how these capacities inform our understanding of what people came to value in the material dimension, we move beyond a simple description of the capacities within the assemblage towards an appreciation of the human personae which valued particular capacities. This is beyond a descriptive totalizing narrative, but has potential as an explanatory technique in looking at how capacities may combine in novel or even polyvalent manners in the emergence of specific communities (on polyvalence, see Robinson 2013c). This avoids the dead-end trap of reifying assemblage theory as a totalizing metanarrative or tautology while promoting DeLanda's mantra of assemblages against totalities. 


\section{Acknowledgements}

I thank Julienne Bernard, Rick Bury, Carole Bury, D.C. Clendenen, Sheryl Clendenen, Michael Glassow, John Johnson, Unika Delpino-Mark, Rick Peterson, Vicki Cummings, James Morris, Dan Reeves, Jack Sprague, Fraser Sturt, Michelle Wienhold, plus all the team members on the Cache Cave project. Thanks also to Ed Jolie for his insights into the basketry collection. Special thanks to Dan York of the Wildlands Conservancy and the staff of the Wind Wolves Preserve for their permission and kind support for this research. Finally, thanks to Yannis Hamilakis and Andy Jones for their invitation to submit this paper. Support for work at Cache Cave has been supplied by an American Philosophical Society Franklin Grant, the British Academy (SG113046), the Institute for Field Research, and the University of Central Lancashire.

David Robinson

School of Forensic and Applied Sciences University of Central Lancashire

Preston PR1 2HE

Email: dwrobinson@uclan.ac.uk

\section{References}

Anderson, B., M. Kearnes, C. McFarlane \& D. Swanton, 2012. Materialism and the politics of assemblage. Dialogues in Human Geography 2(2), 212-15.

Arnold, J. (ed.), 2001. The Origins of a Pacific Coast Chiefdom: The Chumash of the Channel Islands. Salt Lake City (UT): University of Utah Press.

Bennett, J., 2010. Vibrant Matter: A political ecology of things. Durham/London: Duke University Press.

Biehl, J. \& P. Locke, 2010. Deleuze and the anthropology of becoming. Current Anthropology 51(3), 317-51.

Bird-David, N., 1999. 'Animism' revisited: personhood, environment, and relational epistemology. Current Anthropology 40(1), S67-92.

Blackburn, T., 1975. December's Child: A book of Chumash oral narratives. Berkeley (CA): University of California Press.

DeLanda, M., 2002. Deleuzian Ontology: A Sketch. Presented at New Ontologies: Transdisciplinary Objects, March 30, University of Illinois. http://www.situation.ru/app/j_art_1078.htm

DeLanda, M., 2006. A New Philosophy of Society: assemblage theory and social complexity. London: Bloomsbury. 
DeLanda, M., 2011. Philosophy and simulation: the emergence of synthetic reason. London: Bloomsbury.

DeLanda, M., 2012. Emergence, causality and realism. Architectural Theory Review 17(1), 3-16.

DeLanda, M., 2016. Assemblage Theory. Edinburgh: Edinburgh University Press.

Deleuze, G. \& F. Guattari, 1987. A Thousand Plateaus. Capitalism and schizophrenia (Trans B. Massumi). Minneapolis (MN): University of Minnesota Press.

DeMarrias, E. 2013. Understanding heterarchy: crafting and social products in PreHispanic northwest Argentina. Cambridge Archaeological Journal 23(3), 345-362.

Dowson, T., 2007. Debating shamanism in southern African rock art: time to move on ... The South African Archaeological Bulletin 62(185), 49-61.

Dowson, T., 2009. Re-animating hunter-gatherer rock-art research. Cambridge Archaeological Journal 19(3), 378-87.

Escobar, A., 2007. The 'ontological turn' in social theory. A commentary on 'Human geography without scale', by Sallie Marston, John Paul Jones II and Keith Woodward. Transactions of the Institute of British Geographers n.s. 32(1), 106-11.

Escobar, A. \& M. Osterweil, 2010. Social movements and the politics of the virtual: Deluezian strategies, in Deleuzian Intersections: Science, technology, anthropology, eds. C.B. Jensen \& K. Rödje. New York/Oxford: Berghahn Books, 187-218.

Fowler, C., 2013. The Emergent Past: A relational realist archaeology of Early Bronze Age mortuary practices. Oxford: Oxford University Press.

Gamble, L., 2008. The Chumash World at European Contact: Power, trade, and feasting among complex hunter-gatherers. Berkeley (CA): University of California Press.

Gibson, J.J., 1979. The Ecological Approach to Visual Perception. New York (NY): Psychology Press.

Gillings, M., 2012. Landscape phenomenology, GIS and the role of affordance. Journal of Archaeological Method and Theory 19(4), 601-11.

Graeber, D. 2001. Toward an Anthropological Theory of Value: The false coin of our own dreams. New York (NY): Palgrave Macmillan.

Harrison, R., 2011. Surface assemblages. Towards an archaeology in and of the present. Archaeological Dialogues 18(2), 141-61.

Hudson, T., T.C. Blackburn, R. Curletti \& J. Timbrook (eds.), 1977. The Eye of the Flute: Chumash traditional history and ritual as told by Fernando Librado Kitsepawit to John P. Harrington. Banning (CA): Malki Museum Press.

Ingold, T. 2011. Being Alive: Essays on movement, knowledge and description. London: Routledge.

Ingold, T., 2014. Is there life amidst the ruins? Journal of Contemporary Archaeology $1(2), 231-5$.

Latour, B., 2005. Reassembling the Social. An introduction to actor-network theory. Oxford: Oxford University Press.

Lock, G., M. Kormann, \& J. Pouncett. 2014. Visibility and movement: towards a GIS-based integrated approach, in Computational approaches to the study of movement in archaeology: theory, practice, and interpretation on factors and effects of 
long term formation and transformation, eds. S. Polla \& P. Verhagen. Berlin: De Gruyter, 23-42.

Mohr, A. \& L.L. Sample, 1967. The sacred bundle complex among the Chumash. Proceedings of the American Philosophical Society 111(1), 38-46.

Normark, J., 2009. The making of a home: assembling houses at Nohcacab, Mexico. World Archaeology 41(3), 430-44.

Normark, J., 2010. Involutions of materiality: operationalizing a Neo-materialist perspective through the causeways at Ichmul and Yo'okop. Journal of Archaeological Method and Theory 17, 132-73.

Pauketat, T.R., 2013. Bundles of/in/as time, in Big Histories, Human Lives: Tackling problems of scale in archaeology, (eds.) J. Robb \& T.R. Pauketat. Santa Fe (NM): School of Advanced Research Press, 35-56.

Robinson, D.W., 2004. The mirror of the sun: surface, mineral applications, and interface in California rock art, in Soils, Stones and Symbols: Archaeological and anthropological perspectives on the mineral world, eds. N. Boivin \& M.A. Owoc. London: UCL Press, 91-106.

Robinson, D.W., 2007. Taking the bight out of complexity: elaborating south-central California interior landscapes, in Socialising Complexity: Structure, integration, and power, eds. S. Kohring \& S. Wynne-Jones. Oxford: Oxbow, 183-204.

Robinson, D.W., 2013a. Transmorphic being, corresponding affect: ontology and rock-art in south-central California, in Archaeology After Interpretation: Returning materials to archaeological theory, eds. B. Alberti, A. Jones \& J. Pollard. Walnut Creek (CA): Left Coast Press, 59-78.

Robinson, D.W., 2013b. Drawing upon the past: temporal ontology and mythological ideology in south-central Californian rock-art. Cambridge Archaeological Journal 23(3), 373-94.

Robinson, D.W., 2013c. Polyvalent metaphors in south-central Californian missionary processes. American Antiquity 78(2), 302-21.

Robinson, D.W., W. Whitby \& M. Wienhold, 2012. California: from boundaries to networks, in Contemporary Issues in California Archaeology, eds. T.L. Jones \& J. Perry. Walnut Creek (CA): Left Coast Press, 273-93.

Robinson, D.W. \& M. Wienhold, 2016. Household networks and emergent territory: a GIS study of Chumash households, villages, and rock-art in south-central California. World Archaeology. DOI: 10.1080/00438243.2016.1185378

Shanks, M., 2007. Symmetrical archaeology. World Archaeology 39(4), 589-96.

Shanks, R., 2010. California Indian Baskets: San Diego to Santa Barbara and beyond to the San Joaquin Valley, mountains and deserts. Seattle (WA): University of Washington Press.

Timbrook, J., 2007. Chumash Ethnobotany: Plant Knowledge among the Chumash people of Southern California. (Santa Barbara Museum of Natural History Monograph 5/Publication in Anthropology 1.) Berkeley (CA): Heyday Books.

van der Veen, M., 2014. The materiality of plants: plant-people entanglements. World Archaeology 46(5), 799-812. 
Whitby, W. 2012. Wrapped in Meaning: Chumash Cache Caves. Unpublished Ph.D thesis, University of Central Lancashire.

Witmore, C.L., 2007. Symmetrical archaeology: excerpts of a manifesto. World Archaeology 39(4), 546-62.

Zedeño, M.N., 2008. Bundled worlds: the roles and interactions of complex objects from the North American Plains. Journal of Archaeological Method and Theory 15(4), 362-78.

\section{Author biography}

David Robinson is a Reader in Archaeology at the University of Central Lancashire. He has been the lead PI for the Enculturating Environments Project, which excavated a series of rock-art locales in south-central California, and is currently the lead PI for the Gordian Knot Project, which is using portable analytical instrumentation to analyse the most complex pictographs in North America. He also is lead PI for the Cache Cave Project.

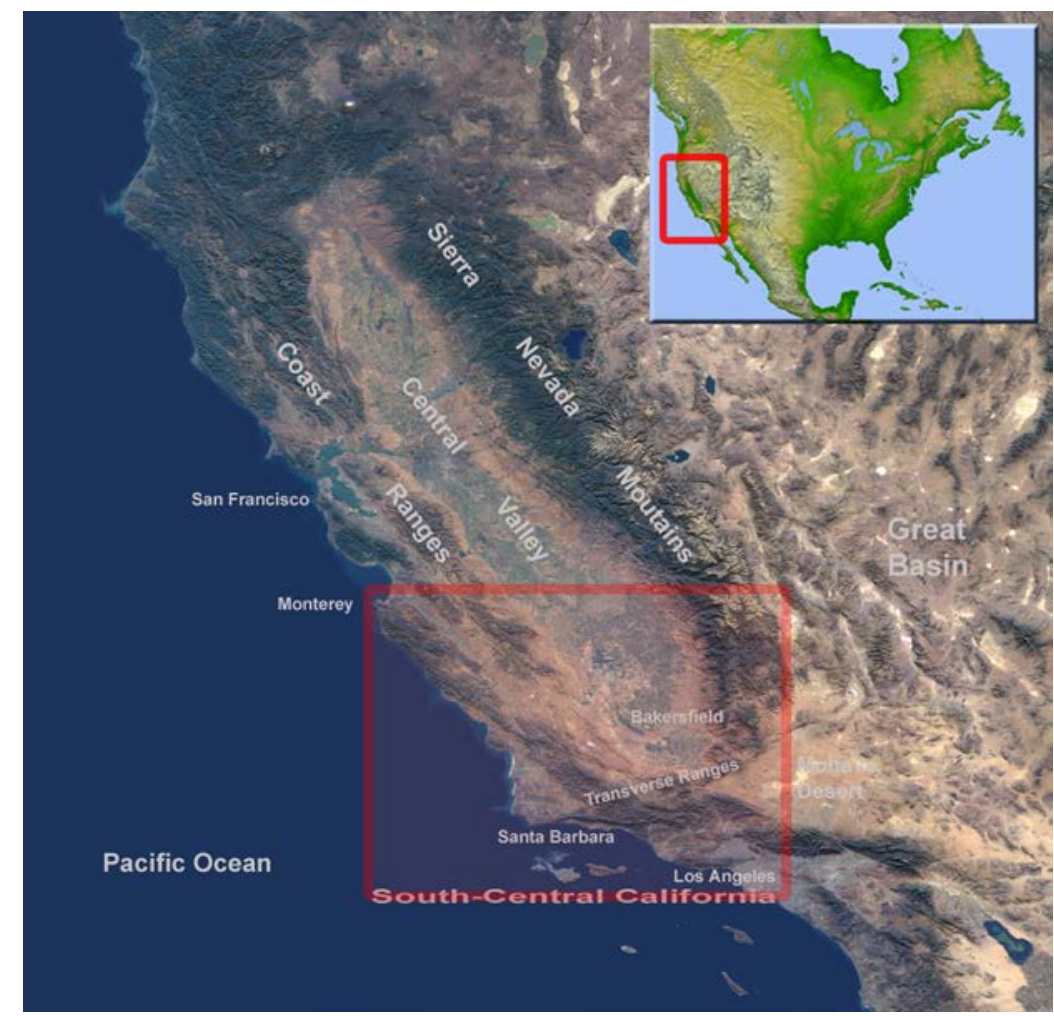

Figure 1. South California with location of major cities and geomorphic features. (Source: NASA \& USGS.) 


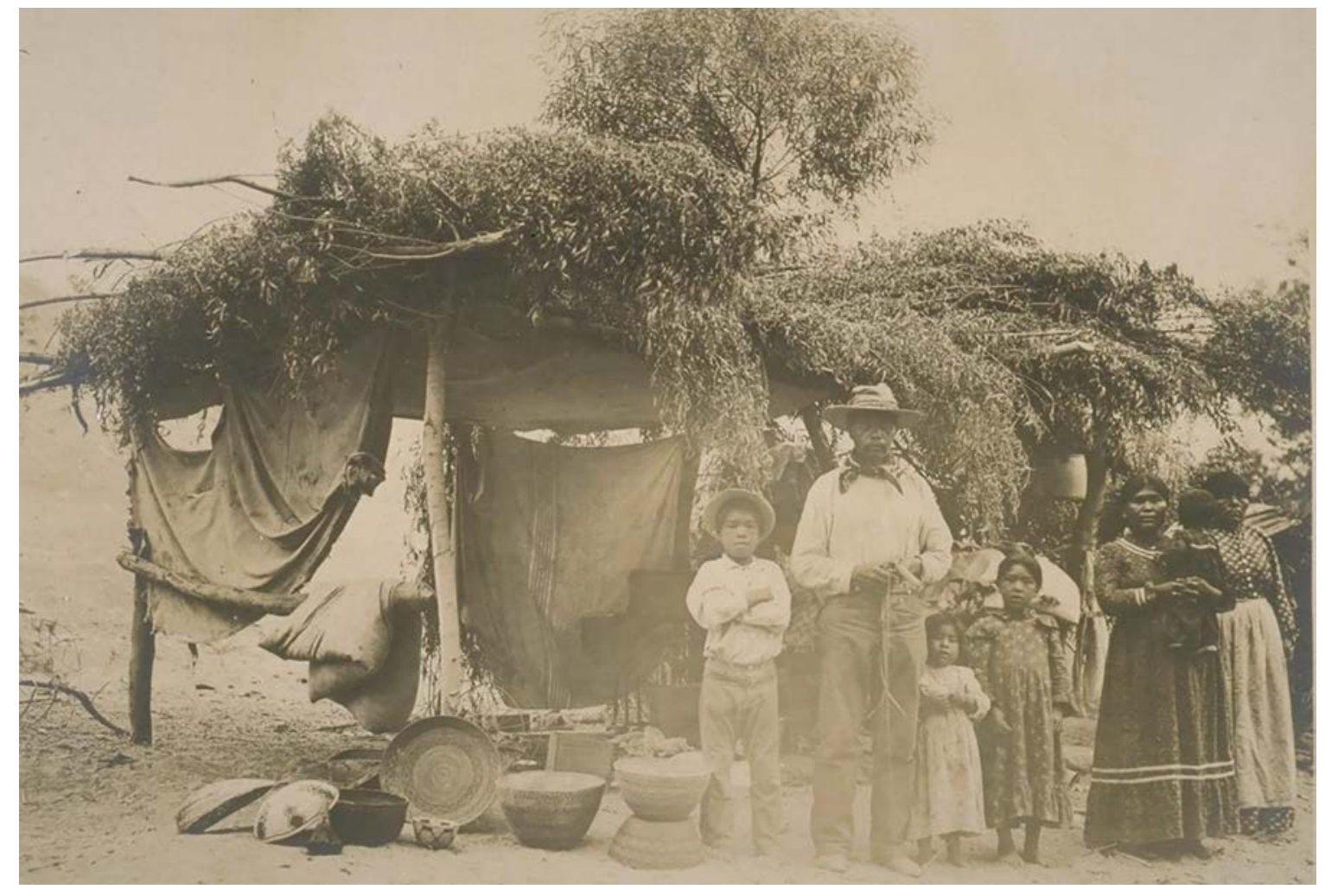

Figure 2. Yokuts household, Kawia River, with household basketry on display. No date provided. (From C. Hart Merriam Collection of Native American Photographs, courtesy of UC Berkeley, Bancroft Library.) 


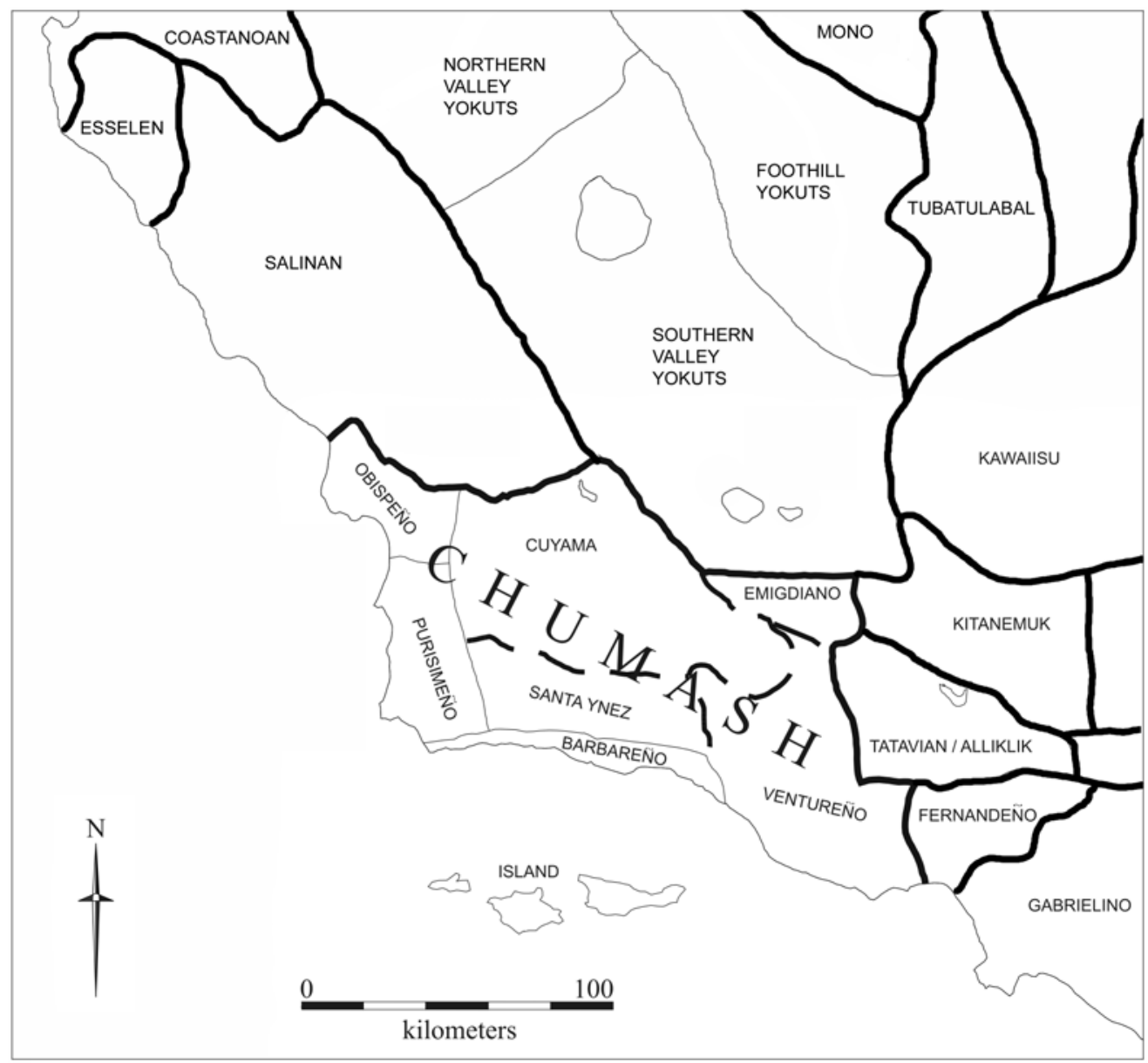

Figure 3. The Chumash, their linguistic subdivisions, and neighbours. (Ian Forbes and David Robinson.) 


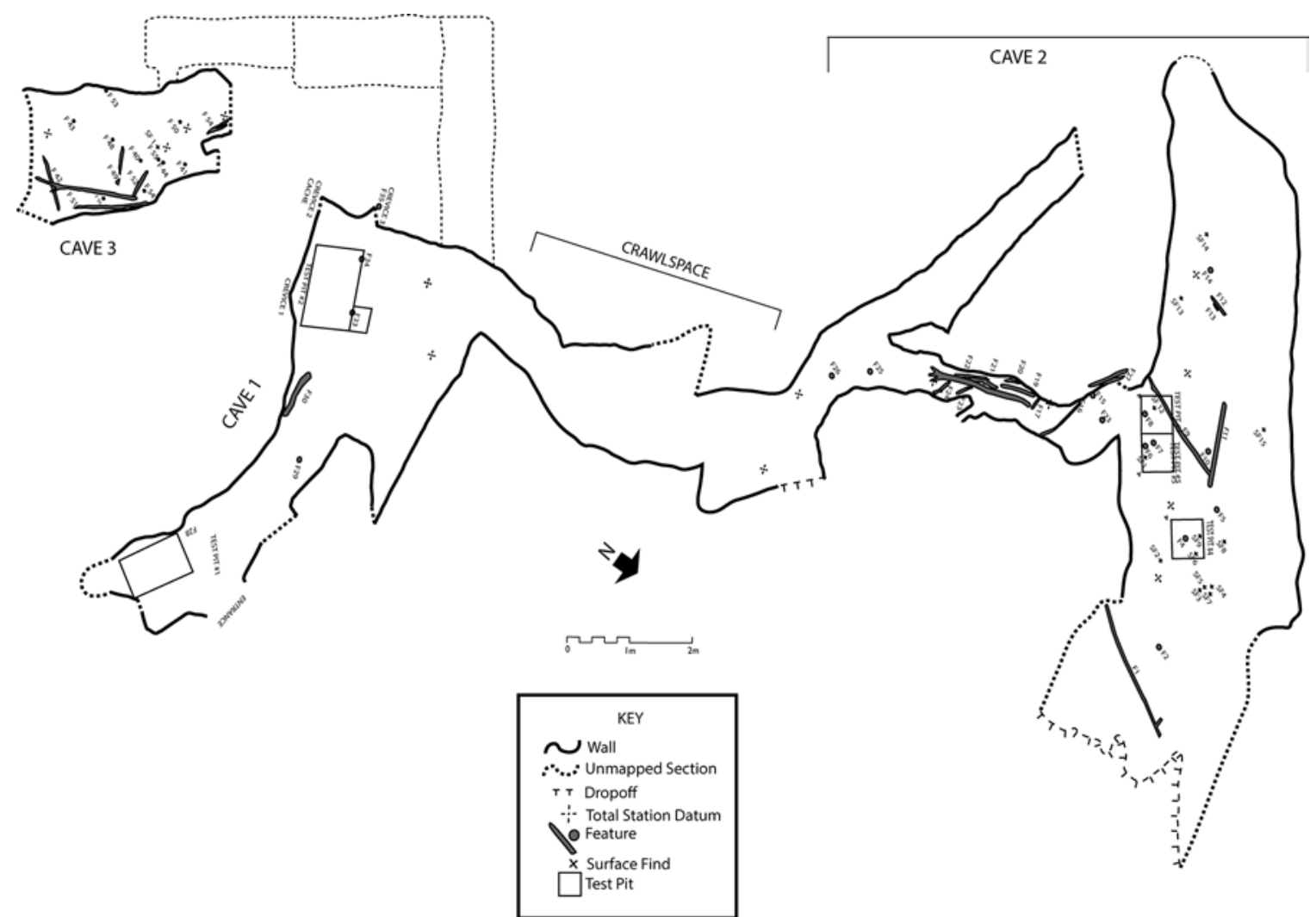

Figure 4. Map of Cache Cave, Caves 1, 2, and 3 (Cave 4 not shown). (Michelle Wienhold and Melonie Shier.)

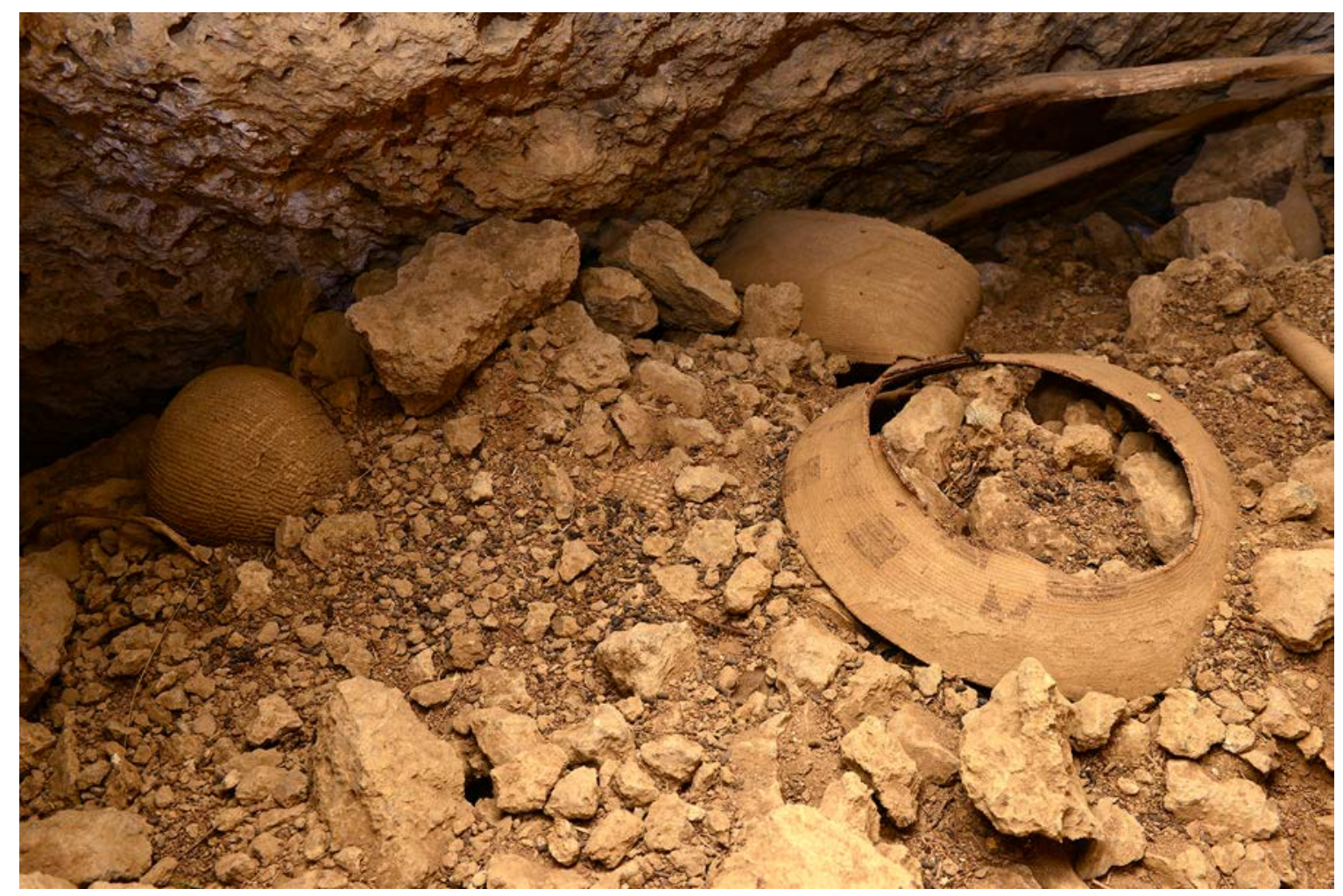

Figure 5. Artefacts as discovered, Cache Cave, Cave 3. (Photograph: Rick Bury.) 

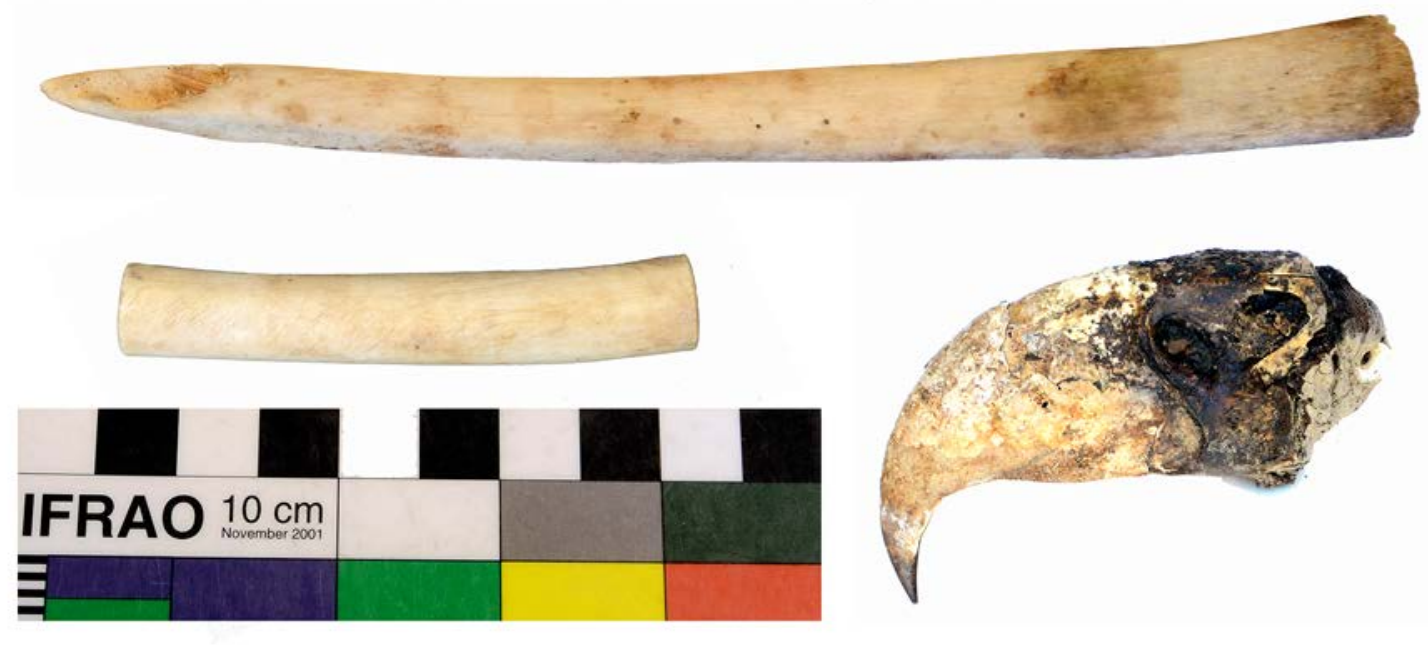

Figure 6. Assemblage from Cache Cave, Crevice 1, Cave 1. Modified deer rib (top); polished coyote femur (bottom right); bald eagle beak, plugged with asphaltum with two embedded olivella shell beads. (Photographs: D.C. Clendenen and Rick Bury.)

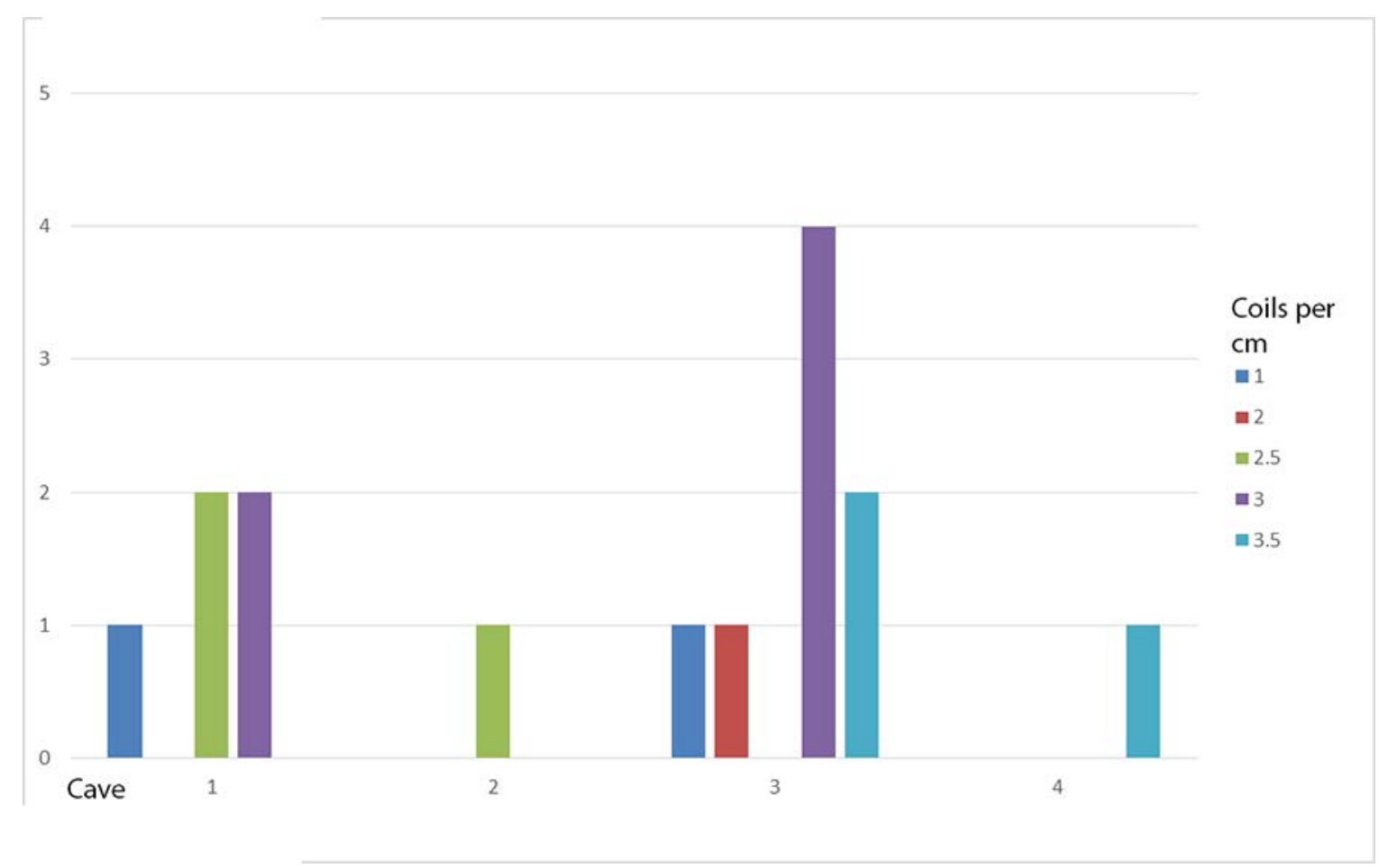

Figure 7. Coil density of sampled basketry vessels from Cache Cave (Caves 1, 2, 3, E 4). 
4

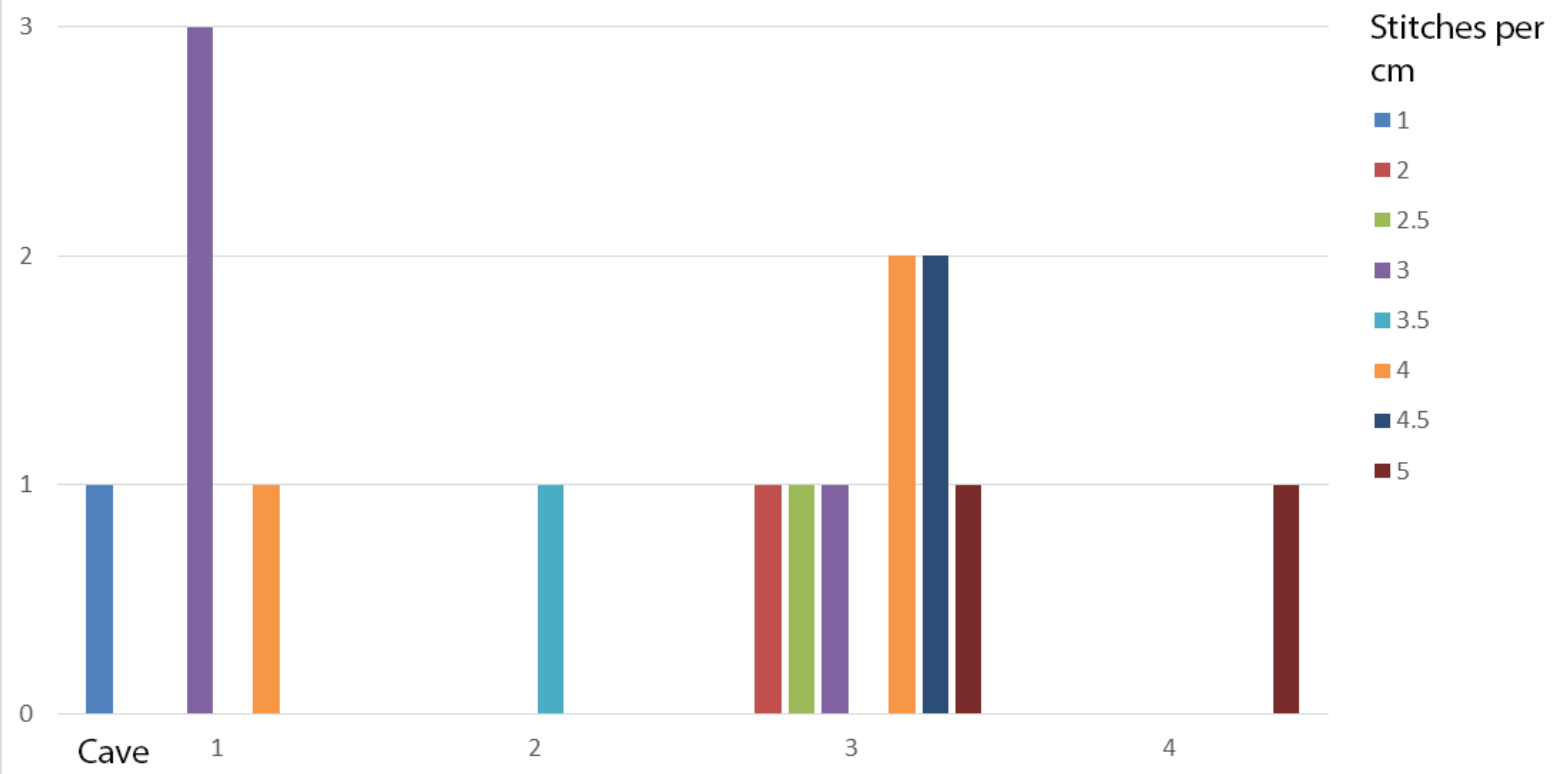

Figure 8. Stitch density of sampled basketry vessels from Cache Cave (Caves 1, 2, 3, \& 4). 


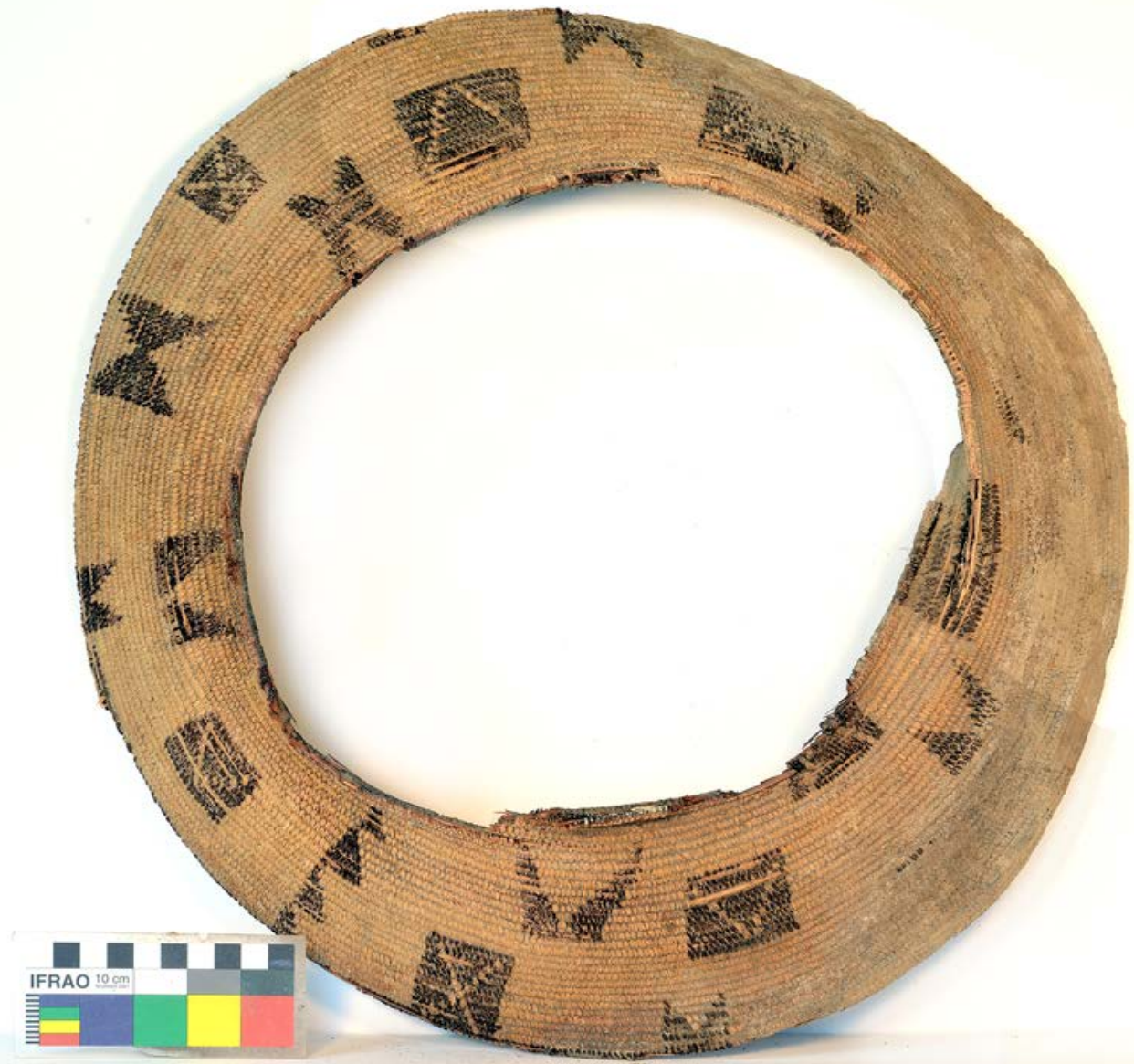

Figure 9. Decorated coiled tray rim, Cache Cave, Cave 3. (Photograph: Rick Bury.) 